\title{
Translation Process Protein
}

National Cancer Institute

\section{Source}

National Cancer Institute. Translation Process Protein. NCI Thesaurus. Code C38576.

Proteins that participate in functions at the ribosome whereby the information in mRNA is used to specify the sequence of amino acids in a nascent polypeptide chain. 